\title{
ESTRATÉGIAS ARQUITETÔNICAS DE CONFORTO TÉRMICO EM PROJETOS DE EDIFÍCIOS VERTICAIS
}

\author{
Amilcar José Bogo ${ }^{*}$, Isadora Hildebrand Pickler
$\begin{gathered}\text { Universidade Regional de Blumenau - Depto de Arquitetura e Urbanismo - Laboratório de Conforto Ambiental } \\ \text { bogo.amilcar@gmail.com }{ }^{*}\end{gathered}$
Submetido $26 / 06 / 2016$ - Aceito $11 / 04 / 2017$
DOI: $10.15628 /$ holos.2017.4753
}

\section{RESUMO}

Neste artigo são apresentados os resultados de uma avaliação das estratégias arquitetônicas de conforto ambiental térmico presentes numa amostra de projetos de edifícios verticais. As edificações analisadas são de uso residencial e serviços e estão localizadas em quatro (4) cidades de Santa Catarina (Blumenau, Florianópolis/São José, Joinville). A análise foi realizada a partir de material de divulgação publicado em anúncios de jornais e sítios da internet. O método enfocou a avaliação de sessenta e dois (62) projetos com base na avaliação das estratégias de conforto ambiental térmico referente ao controle solar nas aberturas, ventilação natural, uso da luz natural e tratamento paisagístico exterior. A avaliação desta amostra de projetos de edificações possibilitou compreender como está parte da produção arquitetônica nestas três cidades, no que se refere ao conforto ambiental no projeto, aspecto fundamental da qualidade arquitetônica. Ao final, observou-se uma situação de inadequação quanto à maior parte dos quesitos de análise, principalmente quanto ao controle solar nas aberturas, revelando falhas do projeto de arquitetura.

PALAVRAS-CHAVE: Conforto ambiental, Controle solar, Estratégias arquitetônicas de projeto.

\section{ARCHITECTURAL STRATEGIES OF THERMAL COMFORT IN VERTICAL BUILDINGS}

\begin{abstract}
This paper presents the results of an analysis of the architectural strategies for environmental comfort present in the architectural design of vertical buildings. The buildings were located in four (4) cities of Santa Catarina state (Blumenau, Florianópolis/São José, Joinville). The analysis was performed from promotional material published in newspapers ads and websites. The method focused on the evaluation of sixty-two (62) building architectural design based on the evaluation of environmental thermal comfort strategies related to
\end{abstract}

solar control the openings, natural ventilation, daylight use and outdoor landscaping. The evaluation of this sample buildings architectural design enabled us to understand how is the architectural production in the three cities, with regard to environmental comfort in architectural design, fundamental aspect of architectural quality. Results show inadequacy in most analysis topics, particularly solar control in openings, revealing errors in architectural design.

KEYWORDS: Thermal comfort, Solar control, Architectural design strategies. 


\section{INTRODUÇÃO}

O conforto ambiental nas edificações é umas das premissas básicas da boa arquitetura, seja qual for à tipologia ou linguagem arquitetônica adotada. No entanto, boa parte da produção arquitetônica na cidade não apresenta condições de conforto ambiental adequadas por falhas de projeto, ou se limita a atender aos requisitos de projeto relacionados somente a morfologia, funcionalidade e estética, numa redução dos compromissos da arquitetura com o ser humano. As respostas arquitetônicas adequadas ao conforto ambiental no projeto ocorrem majoritariamente a partir de ações referentes a situações de implantação da edificação no terreno, forma da edificação, controle solar nas aberturas, uso da luz natural, ventilação natural, desempenho térmico de coberturas e paredes e tratamento paisagístico exterior.

Dependendo da situação de cada projeto em relação ao terreno, programa de necessidades, legislação urbanística, algumas destas ações de projeto não podem ser experimentadas, ficando para as demais as respostas adequadas de projeto arquitetônico quanto ao conforto ambiental, no caso o controle solar nas aberturas, a ventilação natural, o uso adequado da luz natural e o tratamento paisagístico exterior.

No que se refere ao conforto ambiental, uma melhor relação da edificação com o clima é importante. De acordo com Gutierrez e Labaki (2005), "A adequação das edificações ao clima é uma condicionante de projeto". Neste sentido, as estratégias bioclimáticas proporcionam a adequação da arquitetura ao clima, aliando entre outras, elementos de proteção solar a componentes que permitam a ventilação natural adequada aos ambientes.

Para a melhoria do conforto ambiental dos ocupantes das edificações, uma das principais estratégias de projeto é a proteção do excesso de insolação nas aberturas, a partir de diferentes estratégias e elementos arquitetônicos.

Para se proteger do excesso da radiação solar incidente, existem três estratégias básicas: dispositivo de proteção interna à janela, materiais transparentes com características especiais e dispositivo externo ao edifício. Os dispositivos externos de proteção têm a capacidade de interceptar os raios solares antes que atinjam as superfícies envidraçadas (MARAGNO, 2001).

Dentre os dispositivos externos à janela, citam-se diversos tipos como: marquise, persiana externa, veneziana, pergolado, beiral, brise-soleil, sacada, elemento vazado, laje em balanço, telas/toldos, treliçado, painel opaco, varanda, grelha, painel perfurado.

As diversas vantagens no uso dos brises são: proteger da radiação solar direta, captar a ventilação, refletir e distribuir a luz natural no interior dos ambientes, diminuindo o contraste provocado pelo excesso de iluminação natural próximo às janelas. Bloquear a radiação solar e aproveitar a iluminação e ventilação natural é uma das formas de proporcionar uma adequação essencial ao projeto, buscando evitar o desconforto visual, que pode ser causado por ofuscamento ou contraste, proporcionando a integração eficiente com os sistemas artificiais de condicionamento térmico e iluminação artificial (LIMA et al., 2011).

Após a década de 1960 a utilização do brise-soleil tornou-se cada vez mais escassa, por seu custo, dificuldade de manutenção, desconhecimento técnico, a popularização dos sistemas de condicionamento de ar, no qual as questões de conforto ambiental não eram mais fatores primordiais de concepção, dentre outros. Devido à esta situação, cada vez mais surgiram grandesquantidade de edifícios com aberturas envidraçadas de várias dimensões sem nenhuma 
proteção para diminuir os ganhos térmicos ocasionados pela incidência direta do sol (FONTENELLE; CLARO; ARAúJO, 2011).

Segundo PiccoliJunior et al. (2013) "As proteções solares são mecanismos importantes, pois além de atuarem como prateleiras de luz, ajudam no conforto térmico regulando a quantidade de radiação que entra no ambiente conforme a hora do dia".

Maragno (2001) aborda "os fatores que levaram ao desenvolvimento dos brises por Le Corbusier, sua incorporação e difusão no repertório da arquitetura moderna brasileira". O estudo aponta o brise-soleil como um dispositivo de alto desempenho para oferecer conforto térmico e lumínico ao mesmo tempo racionalizando o consumo de energia. Por outro lado, os brises ao se constituírem em um elemento dos envoltórios assumem papel significativo na determinação da forma final das edificações.

Sobre a caracterização climática destas quatro (4) cidades (Blumenau, Florianópolis/São José, Joinville), identifica-se primeiro sua situação dentro do clima do Estado. O clima de Santa Catarina é definido segundo Köppen como Mesotérmico (C), úmido (f), de verão quente (a) encontrado no litoral, vales e Oeste; e de verão fresco (b), nas zonas mais elevadas da serra e do planalto. Assim, predominam no estado os climas Cfa - com verão quente e Cfb - com verão fresco. SANTA CATARINA (1991). Blumenau localiza-se no Médio Vale do Itajaí, em baixa latitude (14 m), ao lado do Rio Itajaí-Açu, que corta o município. A cidade apresenta segundo Bogo $(1998 ; 2014)$ um rigor térmico diurno anual de 6 períodos de calor, conforme aplicação do Método das Tabelas de Mahoney. A cidade apresenta uma temperatura média anual do ar de $20,1^{\circ} \mathrm{C}$, médias das temperaturas máximas do ar de $27{ }^{\circ} \mathrm{C}$ e médias das temperaturas mínimas do ar de $16,1{ }^{\circ} \mathrm{C}$, com $84 \%$ de umidade média do ar e precipitação anual de $1459 \mathrm{~mm}$. Reconhecidamente, é uma das cidades mais quentes do Estado, com temperaturas do ar elevadas no final da primavera, verão e início do outono (períodos de calor), com pouca ventilação.

Florianópolis e São José localizam-se no litoral centro, a beira-mar e limítrofes. Florianópolis apresenta segundo Bogo $(1998 ;$ 2014) um rigor térmico diurno anual de 3 a 5 períodos de calor, conforme aplicação do Método das Tabelas de Mahoney. A cidade apresenta uma temperatura média anual do ar de $20,5^{\circ} \mathrm{C}$, médias das temperaturas máximas do ar de 24,2 ${ }^{\circ} \mathrm{C}$ e médias das temperaturas mínimas do ar de $17,6{ }^{\circ} \mathrm{C}$, com $82 \%$ de umidade média do ar e precipitação anual de $1557 \mathrm{~mm}$.

Joinville localiza-se próximo ao litoral norte, na isoterma de temperatura média anual de $22{ }^{\circ} \mathrm{C}$ (SANTA CATARINA, 1991), ao lado de São Francisco do Sul no litoral que apresenta segundo Bogo $(1998 ; 2014)$ um rigor térmico diurno anual de 4 períodos de calor, conforme aplicação do Método das Tabelas de Mahoney. Reconhecidamente, é uma das cidades mais quentes do Estado, com grande precipitação.

Dentre as recomendações da aplicação do Método das Tabelas de Mahoney para as três (3) cidades, está a de proteção das aberturas, com o bloqueio da luz solar direta, uma das principais estratégias arquitetônicas de conforto ambiental.

Sobre a avaliação da estratégia de controle solar em edificações em Blumenau, Uliano e Bogo (2013) e Uliano e Bogo (2014) avaliaram edifícios verticais em dois bairros da cidade. Neste último trabalho, os resultados encontrados identificaram que "somente em $67 \%$ dos ambientes de permanência dos apartamentos avaliados existem elementos de controle solar - ECS. Já deste 
percentual de ambientes citados, somente $37 \%$ possuem soluções adequadas, revelando problemas de projeto de arquitetura. De todos os apartamentos analisados, somente $14 \%$ possuem todas as soluções arquitetônicas de controle solar como adequadas."

\section{OBJETIVO}

O objetivo deste artigo é apresentar uma avaliação das estratégias arquitetônicas de conforto ambiental presentes numa amostra de projetos de edificações verticais localizadas em Blumenau, Florianópolis/São José e Joinville.

\section{MÉTODO}

O trabalho foi realizado a partir da análise de material de divulgação publicado em anúncios de jornais e sítios da internet. A maior amostragem foi definida para Blumenau, em função da atuação dos autores deste trabalho de pesquisa nesta cidade.

Para a realização das análises foram realizadas as seguintes ações metodológicas:

1) Seleção da amostra de estudo a partir da identificação dos projetos de edificações verticais (edifícios) publicados em anúncios de jornais e sítios da internet. Também foi realizada uma consulta a jornal diário local (edição de final de semana) visando identificar anúncios de edifícios em construção ou lançamento com apartamentos à venda e material gráfico de anúncio.

Foi também realizada uma pesquisa em sítios da internet que divulgam empreendimentos imobiliários, identificando edifícios em construção ou lançamento com apartamentos à venda;

2) Levantamento dos dados de cada projeto, como plantas baixas, plantas de situação, fachadas, e outras informações sobre cada edifício: com base nos anúncios foi realizado um levantamento das informações gráficas de cada projeto/empreendimento, visando reconhecimento visual dos projetos;

3) Organização das informações de cada edifício em fichas de catalogação: as informações gráficas antes identificadas de cada projeto arquitetônico foram organizadas e adequadas às fichas de catalogação, para posterior análise;

4) Análises das informações gerais e específicas de cada edifício quanto ao conforto ambiental, referente ao controle solar e uso da luz natural nas aberturas, ventilação natural e tratamento paisagístico exterior: cada projeto foi analisado nos aspectos antes citados, com base em critérios de adequação ou não:

- Controle solar nas aberturas \& Uso da luz natural controlada:

Para a avaliação da eficiência dos elementos de controle solar fixos, foram definidos ângulos desejáveis de proteção solar segundo cada orientação: norte $=$ a partir de $60^{\circ}$; nordeste $=$ a partir de $50^{\circ}$; leste $=$ a partir de $40^{\circ} ;$ noroeste $=$ a partir de $50^{\circ} ;$ oeste $=$ a partir de $30^{\circ} ;$ sudoeste $/$ e sudeste/sul = a partir de $30^{\circ}$. Com isto foi possível estimar a profundidade necessária $(P=h / \operatorname{tg} \alpha)$ dos ECS fixos, como varandas, sacadas, marquises, beirais, etc. A partir destes ângulos desejáveis, foi definido como situação adequada de proteção solar se os mesmos apresentassem dimensões mínimas da metade destes valores, até o valor final: no caso de uma porta janela com 2,4 m de altura junto a uma sacada para norte, o valor resultante $\mathrm{P}$ é de $1,39 \mathrm{~m}$, com valor mínimo de $\mathrm{P}=$ $0,69 \mathrm{~m}$; 
Para a avaliação da eficiência dos elementos de controle solar móveis, a própria existência dos mesmos indica adequação, pois abrem e fecham de acordo com as necessidades de maior ou menor bloqueio solar.

- Ventilação natural cruzada: avaliada a partir da análise da planta baixa com referência a possibilidade de fluxos de ar cruzados dentro do apartamento e a partir da existência de ambientes sem ventilação natural;

- Tratamento paisagístico com sombra arbórea: avaliado com base na existência ou não de arborização junto a pavimento térreo, como parte do paisagismo exterior;

Também foi realizada a avaliação geral de desempenho de cada abertura quanto ao controle de excesso de insolação e luminosidade (A), ventilação natural cruzada (B) e visualização exterior (c), segundo a escala de avaliação adiante apresentado nas Tabelas 1 e 2.

Tabela 1: Escala Quali-Quantitativa para avaliação de abertura.

\begin{tabular}{|c|c|c|c|}
\hline \multicolumn{4}{|c|}{ Pesos para Avaliação de cada Abertura } \\
\hline Ótimo & Bom & Regular & Ruim \\
\hline 4 & 3 & 2 & 1 \\
\hline \multicolumn{4}{|c|}{ Fonte: Os autores }
\end{tabular}

Tabela 2: Escala de pontuação para avaliação do desempenho da abertura.

\begin{tabular}{|l|c|c|c|c|}
\hline & \multicolumn{2}{|l|}{ Critérios de Análise } & \\
\hline Avaliação & $\begin{array}{c}\text { A (insolação } \\
\text { e luminosidade }\end{array}$ & $\begin{array}{c}\text { B } \\
\text { (ventilação } \\
\text { cruzada) }\end{array}$ & $\begin{array}{c}\text { C } \\
\text { (visualização } \\
\text { exterior) }\end{array}$ & Pontuação Total \\
\hline Adequado & 3 ou 4 & 3 & 3 ou 4 & 9 a 11 (com mín. 3 para A) \\
\hline Parcial Adequado & 3 & 2 & 3 & 8 (com mín. 3 para A) \\
\hline Parcial Inadequado & 2 & 1 & 2 & 5 \\
\hline Inadequado & 1 & 1 & 1 & 3 \\
\hline
\end{tabular}

Fonte: Os autores

5) Avaliação de cada projeto de edifício e do conjunto da amostra analisada: após a avaliação de cada critério de análise de cada projeto, os mesmos foram organizados no conjunto dos trinta e seis (36) projetos estudados, possibilitando uma visão conjunta dos resultados existentes.

\section{Análise dos Resultados}

Os resultados das avaliações realizadas a partir das análises dos projetos das edificações foram agrupados a partir de fichas de catalogação e análise.

Na Figura 1 é apresentado o conteúdo de uma destas fichas de catalogação a título de exemplo (aleatório) para uma das edificações analisadas, face ao limite de tamanho deste documento. 


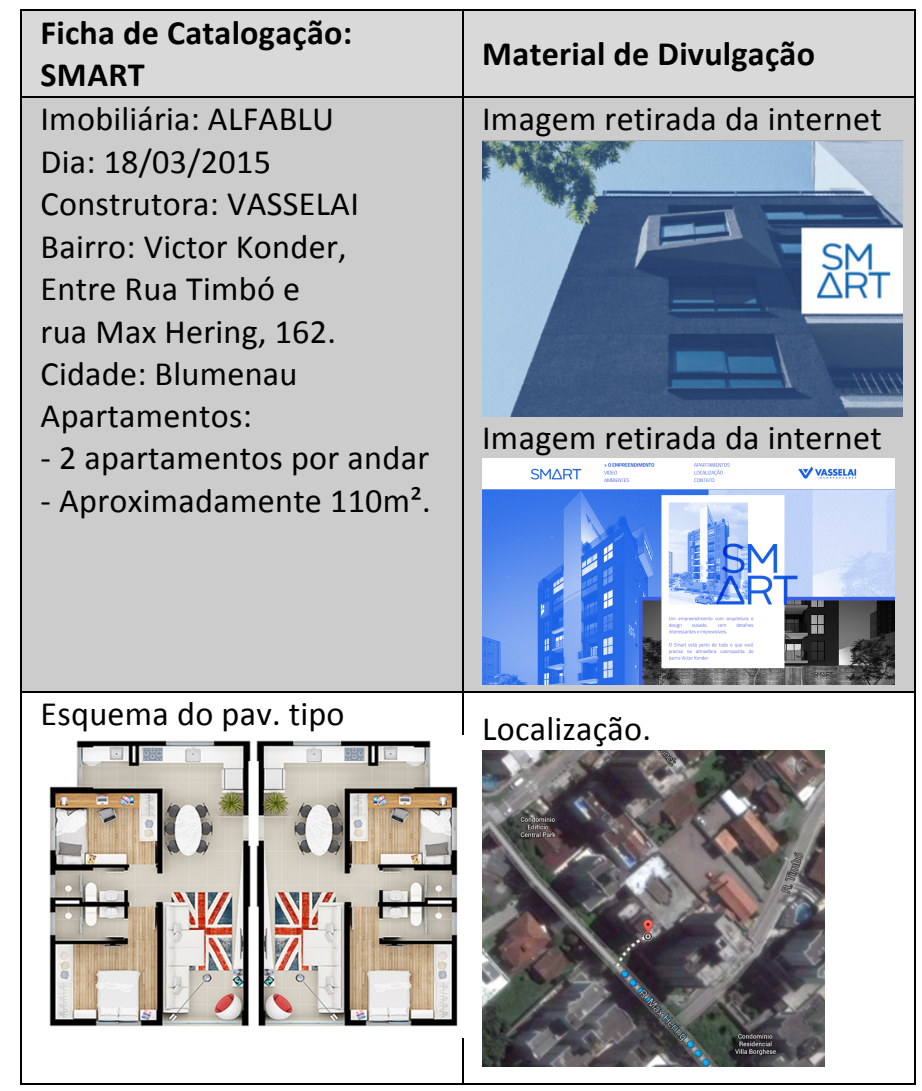

Figura 1: Exemplo de ficha de catalogação de anúncio de internet.

Fonte: Os autores (com base em consulta de material publicitário)

As plantas baixas de cada apartamento como posicionadas no pavimento tipo são adiante apresentadas na Figura 2, entre a área comum do edifício:

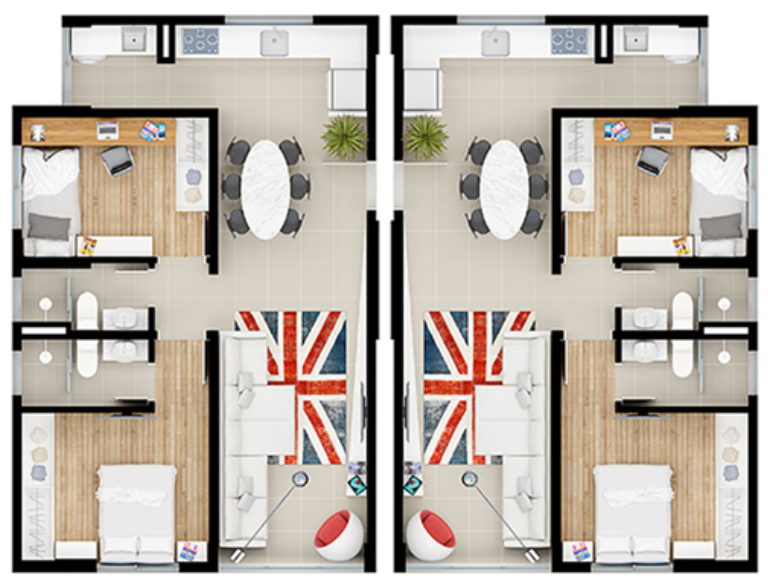

Figura 2: Exemplo das plantas baixas de cada apartamento na posição do pavimento tipo. Apartamentos $1 \mathrm{e}$ Apartamento 2.

Fonte: Os autores (com base em consulta de material publicitário) 
Adiante na Figura 3 é apresentada a vista geral da fachada frontal do Edif. SMART:

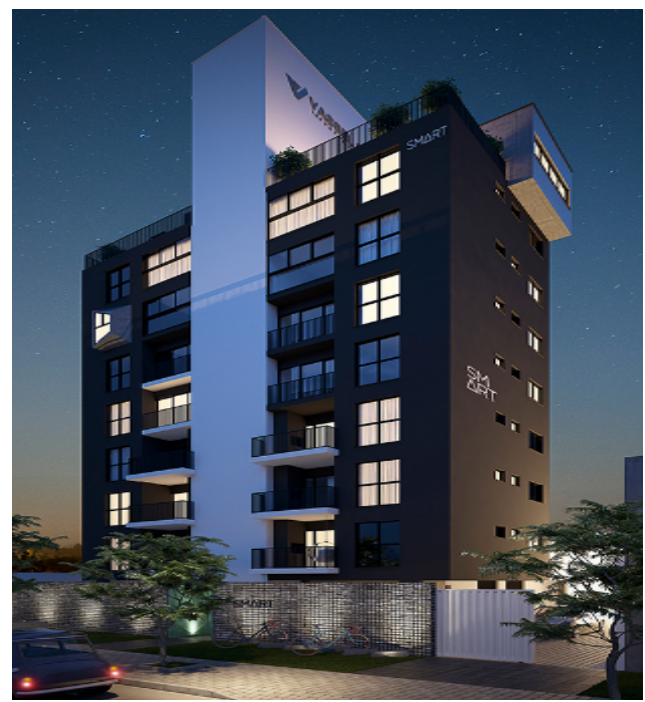

Figura 3: Fachada Frontal Sudoeste

Fonte: Os autores (com base em consulta de material publicitário)

Cada pavimento tipo com os respectivos apartamentos foram analisados quanto à insolação a partir do uso do diagrama solar, conforme adiante apresentado na Figura 4.

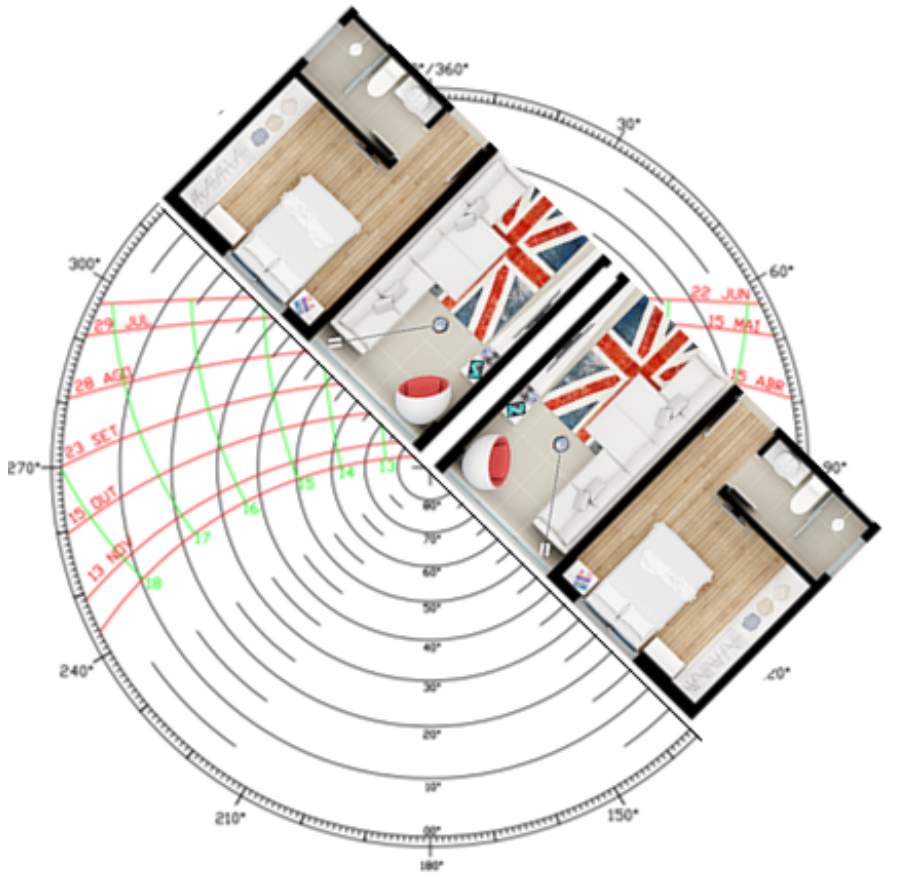

Figura 4: Exemplo de estudo de insolação com uso do diagrama solar para fachada sudoeste do pavimento tipo do Edif. SMART.

Fonte: Os autores

As variáveis de análise controle solar nas aberturas \& uso da luz natural controlada, ventilação natural cruzada, e tratamento paisagístico com sombra arbórea, foram analisadas para cada projeto e são adiante apresentadas na Tabela 3 para o Edif. SMART. 
Tabela 4: Exemplo de ficha de análise de conforto ambiental do apartamento 1

\begin{tabular}{|c|c|c|}
\hline Variáveis de Análise & $\begin{array}{l}\text { Descrição nos } \\
\text { ambientes } \\
\text { de permanência }\end{array}$ & Avaliação Final \\
\hline $\begin{array}{l}\text { Controle solar nas aberturas \& uso da } \\
\text { luz natural controlada: existência ou não de } \\
\text { ECS(móveis e fixos) e sua respectiva } \\
\text { eficiência: } \\
\text { ECS móvel= parcial adequado } \\
\text { ECS fixo= avaliação segundo } \\
\text { Ângulos mínimos de proteção solar }\end{array}$ & $\begin{array}{l}\text { Possui ECS fixo } \\
\text { (sacada) na sala de } \\
\text { estar. } \\
\text { Para SUDOESTE. Mas } \\
\text { apenas nos primeiros } \\
\text { pavimentos possui ECS } \\
\text { fixo (sacada). }\end{array}$ & Inadequado \\
\hline \multirow{2}{*}{$\begin{array}{l}\text { Ventilação natural cruzada: possibilidade de } \\
\text { fluxos de ar cruzados dentro do } \\
\text { apartamento \& existência de ambientes sem } \\
\text { ventilação natural }\end{array}$} & $\begin{array}{l}\text { Ventilação Cruzada: } \\
\text { sala de estar, jantar, } \\
\text { cozinha e dormitórios. }\end{array}$ & Adequado \\
\hline & $\begin{array}{ll}\text { Sem } & \text { Ventilação } \\
\text { Cruzada: } & \\
\text { Não possui. } & \end{array}$ & Adequado \\
\hline $\begin{array}{l}\text { Tratamento paisagístico com sombra } \\
\text { arbórea: arborização junto ao pavimento } \\
\text { térreo, como parte do paisagismo exterior }\end{array}$ & $\begin{array}{l}\text { Não possui área } \\
\text { arborizada no térreo. } \\
\text { Com grandes áreas } \\
\text { livres do terreno } \\
\text { pavimentado. }\end{array}$ & Inadequado \\
\hline
\end{tabular}

Fonte: Os autores

A utilização de elementos de controle solar - ECS nas aberturas dos apartamentos de cada projeto de edifício vertical é adiante apresentada nas Tabelas 5 e 6 :

Tabela 5: Exemplo das estratégias arquitetônicas de controle solar nas aberturas do Edif. SMART.

\begin{tabular}{|c|c|c|c|c|c|}
\hline Apto. & $\begin{array}{c}\text { Ambientes/ } \\
\text { Orientação }\end{array}$ & $\begin{array}{c}\text { Tipo } \\
\text { ECS }\end{array}$ & $\begin{array}{c}\text { Material/ } \\
\text { Profundidade }\end{array}$ & $\begin{array}{c}\text { Profundidade } \\
\text { mínima para } \\
\text { adequação }\end{array}$ & Avaliação \\
\hline 1 & $\begin{array}{c}\text { Setor social } \\
\text { NO e SO }\end{array}$ & Sacada & $1,0 \mathrm{~m}$ & $2,10 \mathrm{~m}$ & Inadequado \\
\hline 2 & $\begin{array}{c}\text { Setor social } \\
\text { SO e NE }\end{array}$ & Sacada & $1,0 \mathrm{~m}$ & $2,10 \mathrm{~m}$ & Inadequado \\
\hline
\end{tabular}

Fonte: Os autores

Tabela 6: Resumo do Edif. SMART quanto às características de controle solar nas aberturas.

\begin{tabular}{|l|c|}
\hline Número de pavimento tipo & 8 \\
\hline Número de apartamentos por pavimento & 2 \\
\hline Ambientes de permanência & $\begin{array}{c}\text { Três (3): dois dormitórios, } \\
\text { sala de estar/jantar. }\end{array}$ \\
\hline $\begin{array}{l}\text { Solução majoritária/ ambiente de ECS } \\
\text { Sacada/Setor Social }\end{array}$ \\
\hline $\begin{array}{l}\text { Percentual de ambiente de permanência com } \\
\text { soluções de ECS por apartamento }\end{array}$ & $33,33 \%$ \\
\hline $\begin{array}{l}\text { Percentual total do ambiente de permanência } \\
\text { com soluções adequadas de ECS }\end{array}$ & $0 \%$ \\
\hline
\end{tabular}




\begin{tabular}{|l|c|}
\hline $\begin{array}{l}\text { Percentual de apartamentos com soluções de } \\
\text { controle solar no edifício. }\end{array}$ & $71,43 \%$ \\
\hline $\begin{array}{l}\text { Percentual de apartamentos com todas as } \\
\text { soluções adequadas de controle solar no } \\
\text { edifício }\end{array}$ & $0 \%$ \\
\hline
\end{tabular}

Fonte: Os autores

Também foi realizada uma avaliação do desempenho geral das aberturas, segundo os três critérios de análise adiante apresentados na Tabela 7, para o exemplo do Edif. SMART.

Tabela 7: Avaliação do desempenho da abertura segundo os critérios de análise A, B e C.

\begin{tabular}{|l|c|}
\hline Desempenho das aberturas & $\begin{array}{c}\text { Resultado do } \\
\text { Edif. SMART }\end{array}$ \\
\hline Controle de excesso de insolação e de luminosidade & 1 \\
\hline Ventilação & 3 \\
\hline Visualização Externa & 3 \\
\hline Somatório & 7 \\
\hline
\end{tabular}

Fonte: Os autores

Obs.: O edifício analisado não possui elemento de controle solar móvel - ECS.

Avaliação final: parcialmente inadequado $=7$.

$\mathrm{Na}$ amostra de estudo foram identificadas somente três (3) edifícios de uso de serviços, sendo os demais de uso residencial. No caso dos edifícios de serviços, não foram identificados vidros especiais para controle solar.

No que se refere ao controle solar nas aberturas, a situação dominante é do uso elementos de controle solar externos do tipo sacadas junto à área social; já no setor íntimo (quartos), em somente 6 projetos existem ECS móveis do tipo persianas externas e $1 \mathrm{com}$ venezianas.

As orientações solares dos edifícios são as mais variadas devido ao tecido urbano existente e o regime fundiário (forma, tamanho dos terrenos e posição da rua).

Na Tabela 8 são apresentados os resultados da avaliação do conjunto de trinta e seis (36) projetos de edifícios avaliados segundo os quesitos de: uso de elementos de controle solar nas aberturas, desempenho geral das aberturas (critérios $A, B, C$ ), ventilação natural cruzada, tratamento paisagístico com sombra arbórea.

Tabela 8: Avaliação final do conjunto de projetos de edifícios analisados.

\begin{tabular}{|c|c|c|c|c|}
\hline \multicolumn{5}{|c|}{ Quesitos de Análise } \\
\hline Edif. & $\begin{array}{l}\text { Uso de Elementos } \\
\text { de Controle Solar } \\
\text { nas Aberturas de } \\
\text { Ambientes de } \\
\text { Permanência }\end{array}$ & $\begin{array}{l}\text { Desempenho } \\
\text { Geral das } \\
\text { Aberturas: } \\
\text { Critérios A, B e C }\end{array}$ & $\begin{array}{l}\text { Ventilação } \\
\text { Natural } \\
\text { Cruzada }\end{array}$ & $\begin{array}{l}\text { Tratamento } \\
\text { Paisagístico } \\
\text { com } \\
\text { Sombra } \\
\text { Arbórea }\end{array}$ \\
\hline \multicolumn{5}{|c|}{ Blumenau: $\mathbf{3 6}$ projetos analisados } \\
\hline 1 & $\begin{array}{l}\text { Sem controle } \\
\text { (fixo e móvel) = } \\
\text { Inadequado }\end{array}$ & $\begin{array}{l}\text { Parcialmente } \\
\text { Inadequado= } 7\end{array}$ & Adequado & Adequado \\
\hline 2 & $\begin{array}{l}\text { Sem controle } \\
\text { (fixo e móvel) }=\end{array}$ & $\begin{array}{l}\text { Parcialmente } \\
\text { Inadequado= } 7\end{array}$ & Inadequado & Inadequado \\
\hline
\end{tabular}




\begin{tabular}{|c|c|c|c|c|}
\hline & Inadequado & & & \\
\hline 3 & $\begin{array}{l}\text { Sem controle = } \\
\text { Inadequado } \\
\text { Com controle móvel = } \\
\text { Adequado }\end{array}$ & Adequado $=9$ & Adequado & $\begin{array}{l}\text { Parcial } \\
\text { Adequado }\end{array}$ \\
\hline 4 & $\begin{array}{l}\text { Sem controle } \\
\text { (fixo e móvel) = } \\
\text { Inadequado } \\
\text { Com controle móvel = } \\
\text { Adequado }\end{array}$ & $\begin{array}{l}\text { Parcialmente } \\
\text { Inadequado= } 7\end{array}$ & Adequado & $\begin{array}{l}\text { Parcial } \\
\text { Adequado }\end{array}$ \\
\hline 5 & $\begin{array}{l}\text { Com controle }= \\
\text { Inadequado }- \text { Sacada } \\
\text { Com controle = } \\
\text { Adequado }\end{array}$ & Adequado $=9$ & Inadequado & Inadequado \\
\hline 6 & $\begin{array}{l}\text { Com controle = } \\
\text { Adequado -BriseHoriz. } \\
\text { Sem controle móvel = } \\
\text { Inadequado }\end{array}$ & $\begin{array}{l}\text { Parcialmente } \\
\text { Inadequado= } 7\end{array}$ & Adequado & $\begin{array}{l}\text { Parcial } \\
\text { Adequado }\end{array}$ \\
\hline 7 & $\begin{array}{l}\text { Com controle = } \\
\text { Adequado- BriseHoriz. } \\
\text { Sem controle móvel = } \\
\text { Inadequado }\end{array}$ & $\begin{array}{l}\text { Parcialmente } \\
\text { Inadequado }=7\end{array}$ & Adequado & $\begin{array}{l}\text { Parcial } \\
\text { Adequado }\end{array}$ \\
\hline 8 & $\begin{array}{l}\text { Com controle = } \\
\text { Inadequado - Sacada } \\
\text { Sem controle móvel = } \\
\text { Inadequado }\end{array}$ & $\begin{array}{l}\text { Parcialmente } \\
\text { Inadequado= } 7\end{array}$ & Adequado & $\begin{array}{l}\text { Parcial } \\
\text { Adequado }\end{array}$ \\
\hline 9 & $\begin{array}{l}\text { Com controle = } \\
\text { Inadequado }- \text { Sacada } \\
\text { Com controle = } \\
\text { Adequado (Persiana } \\
\text { externa para quartos) }\end{array}$ & $\begin{array}{l}\text { Parcialmente } \\
\text { Inadequado= } 7\end{array}$ & Inadequado & $\begin{array}{l}\text { Parcial } \\
\text { Adequado }\end{array}$ \\
\hline 10 & $\begin{array}{l}\text { Com controle = } \\
\text { Inadequado }- \text { Sacada } \\
\text { Sem controle móvel = } \\
\text { Inadequado }\end{array}$ & $\begin{array}{l}\text { Parcialmente } \\
\text { Inadequado= } 7\end{array}$ & Adequado & $\begin{array}{l}\text { Parcial } \\
\text { Adequado }\end{array}$ \\
\hline 11 & $\begin{array}{l}\text { Com controle = } \\
\text { Inadequado - Sacada } \\
\text { Sem controle móvel = } \\
\text { Inadequado }\end{array}$ & $\begin{array}{l}\text { Parcialmente } \\
\text { Inadequado }=7\end{array}$ & Adequado & Inadequado \\
\hline 12 & $\begin{array}{l}\text { Com controle = } \\
\text { Inadequado }- \text { Sacada } \\
\text { Sem controle móvel = } \\
\text { Inadequado }\end{array}$ & $\begin{array}{l}\text { Parcialmente } \\
\text { Inadequado= } 7\end{array}$ & Adequado & $\begin{array}{l}\text { Parcial } \\
\text { Adequado }\end{array}$ \\
\hline 13 & $\begin{array}{l}\text { Com controle = } \\
\text { Inadequado - Sacada } \\
\text { Sem controle móvel = } \\
\text { Inadequado }\end{array}$ & $\begin{array}{l}\text { Parcialmente } \\
\text { Inadequado= } 7\end{array}$ & Adequado & $\begin{array}{l}\text { Parcial } \\
\text { Adequado }\end{array}$ \\
\hline 14 & $\begin{array}{l}\text { Com controle = } \\
\text { Inadequado - Sacada } \\
\text { Sem controle móvel = } \\
\text { Inadequado }\end{array}$ & $\begin{array}{l}\text { Parcialmente } \\
\text { Inadequado }=7\end{array}$ & Adequado & $\begin{array}{l}\text { Parcial } \\
\text { Adequado }\end{array}$ \\
\hline
\end{tabular}




\begin{tabular}{|c|c|c|c|c|}
\hline 15 & $\begin{array}{l}\text { Com controle = } \\
\text { Inadequado - Sacada } \\
\text { Sem controle móvel = } \\
\text { Inadequado }\end{array}$ & $\begin{array}{l}\text { Parcialmente } \\
\text { Inadequado= } 7\end{array}$ & Inadequado & Inadequado \\
\hline 16 & $\begin{array}{l}\text { Com controle = } \\
\text { Inadequado }- \text { Sacada } \\
\text { Com controle = } \\
\text { Adequado }\end{array}$ & $\begin{array}{l}\text { Parcialmente } \\
\text { Inadequado= } 7\end{array}$ & Inadequado & Inadequado \\
\hline 17 & $\begin{array}{l}\text { Sem controle = } \\
\text { Inadequado } \\
\text { Sem controle móvel = } \\
\text { Inadequado }\end{array}$ & $\begin{array}{l}\text { Parcialmente } \\
\text { Inadequado= } 7\end{array}$ & Adequado & Inadequado \\
\hline 18 & $\begin{array}{l}\text { Com controle = } \\
\text { Inadequado - Sacada } \\
\text { Sem controle móvel = } \\
\text { Inadequado }\end{array}$ & $\begin{array}{l}\text { Parcialmente } \\
\text { Inadequado= } 7\end{array}$ & Adequado & Inadequado \\
\hline 19 & $\begin{array}{l}\text { Com controle = } \\
\text { Inadequado - Sacada } \\
\text { Sem controle móvel = } \\
\text { Inadequado }\end{array}$ & $\begin{array}{l}\text { Parcialmente } \\
\text { Inadequado= } 7\end{array}$ & Adequado & Inadequado \\
\hline 20 & $\begin{array}{l}\text { Com controle = } \\
\text { Inadequado (Sacada } \\
\text { para salas) } \\
\text { Com controle = } \\
\text { Adequado } \\
\end{array}$ & $\begin{array}{l}\text { Parcialmente } \\
\text { Inadequado }=7\end{array}$ & Adequado & Inadequado \\
\hline 21 & $\begin{array}{l}\text { Com controle = } \\
\text { Inadequado - Sacada } \\
\text { Sem controle móvel = } \\
\text { Inadequado }\end{array}$ & $\begin{array}{l}\text { Parcialmente } \\
\text { Inadequado= } 7\end{array}$ & Adequado & Inadequado \\
\hline 22 & $\begin{array}{l}\text { Com controle = } \\
\text { Adequado }- \text { Sacada } \\
\text { Sem controle móvel = } \\
\text { Inadequado }\end{array}$ & Adequado $=9$ & Adequado & Inadequado \\
\hline 23 & $\begin{array}{l}\text { Com controle = } \\
\text { Adequado }- \text { Sacada } \\
\text { Sem controle móvel = } \\
\text { Inadequado }\end{array}$ & $\begin{array}{l}\text { Parcialmente } \\
\text { Inadequado= } 7\end{array}$ & Adequado & Inadequado \\
\hline 24 & $\begin{array}{l}\text { Com controle = } \\
\text { Adequado - Sacada } \\
\text { Sem controle móvel = } \\
\text { Inadequado }\end{array}$ & $\begin{array}{l}\text { Parcialmente } \\
\text { Inadequado= } 7\end{array}$ & Adequado & $\begin{array}{l}\text { Parcial } \\
\text { Adequado }\end{array}$ \\
\hline 25 & $\begin{array}{l}\text { Com controle = } \\
\text { Inadequado - Sacada } \\
\text { Sem controle móvel = } \\
\text { Inadequado }\end{array}$ & $\begin{array}{l}\text { Parcialmente } \\
\text { Inadequado= } 7\end{array}$ & Adequado & $\begin{array}{l}\text { Parcial } \\
\text { Adequado }\end{array}$ \\
\hline 26 & $\begin{array}{l}\text { Com controle = } \\
\text { Inadequado }- \text { Sacada } \\
\text { Com controle = } \\
\text { Adequado }\end{array}$ & $\begin{array}{l}\text { Parcialmente } \\
\text { Inadequado= } 7\end{array}$ & Adequado & Inadequado \\
\hline 27 & $\begin{array}{l}\text { Com controle }= \\
\text { Adequado - Sacada }\end{array}$ & $\begin{array}{l}\text { Parcialmente } \\
\text { Inadequado= } 7\end{array}$ & Adequado & $\begin{array}{l}\text { Parcial } \\
\text { Adequado }\end{array}$ \\
\hline
\end{tabular}




\begin{tabular}{|c|c|c|c|c|}
\hline & $\begin{array}{l}\text { Sem controle móvel = } \\
\text { Inadequado }\end{array}$ & & & \\
\hline 28 & $\begin{array}{l}\text { Com controle }= \\
\text { Inadequado - Sacada } \\
\text { Possui vidros especiais } \\
\text { para controle solar com } \\
\text { Fator solar de } 43,8 \%= \\
\text { Parcial Adequado } \\
\text { Com controle móvel = } \\
\text { Adequado }\end{array}$ & Adequado $=9$ & Adequado & Inadequado \\
\hline 29 & $\begin{array}{l}\text { Com controle }= \\
\text { Adequado }- \text { Sacada } \\
\text { Com controle = } \\
\text { Adequado }\end{array}$ & $\begin{array}{l}\text { Parcialmente } \\
\text { Inadequado= } 7\end{array}$ & Adequado & Inadequado \\
\hline 30 & $\begin{array}{l}\text { Com controle = } \\
\text { Inadequado - Sacada } \\
\text { Sem controle móvel = } \\
\text { Inadequado }\end{array}$ & $\begin{array}{l}\text { Parcialmente } \\
\text { Adequado }=8\end{array}$ & Adequado & Inadequado \\
\hline 31 & $\begin{array}{l}\text { Com controle = } \\
\text { Inadequado - Sacada } \\
\text { Sem controle móvel = } \\
\text { Inadequado }\end{array}$ & Adequado $=9$ & Adequado & Inadequado \\
\hline 32 & $\begin{array}{l}\text { Com controle = } \\
\text { Inadequado - Sacada } \\
\text { Sem controle móvel = } \\
\text { Inadequado }\end{array}$ & $\begin{array}{l}\text { Parcialmente } \\
\text { Inadequado }=7\end{array}$ & Adequado & Inadequado \\
\hline 33 & $\begin{array}{l}\text { Com controle = } \\
\text { Inadequado - Sacada } \\
\text { Sem controle móvel = } \\
\text { Inadequado }\end{array}$ & $\begin{array}{l}\text { Parcialmente } \\
\text { Inadequado }=7\end{array}$ & Adequado & Inadequado \\
\hline 34 & $\begin{array}{l}\text { Sem controle = } \\
\text { Inadequado } \\
\text { Sem controle móvel = } \\
\text { Inadequado }\end{array}$ & $\begin{array}{l}\text { Parcialmente } \\
\text { Inadequado }=7\end{array}$ & Adequado & Inadequado \\
\hline 35 & $\begin{array}{l}\text { Com controle }= \\
\text { Adequado }- \text { Sacada } \\
\text { Sem controle móvel = } \\
\text { Inadequado }\end{array}$ & $\begin{array}{l}\text { Parcialmente } \\
\text { Inadequado= } 7\end{array}$ & Inadequado & $\begin{array}{l}\text { Parcial } \\
\text { Adequado }\end{array}$ \\
\hline \multicolumn{5}{|c|}{ Florianópolis: 14 projetos analisados } \\
\hline 1 & $\begin{array}{l}\text { Com controle = } \\
\text { Inadequado (Sacada) } \\
\text { Com controle móvel = } \\
\text { Adequado }\end{array}$ & Adequado $=9$ & Adequada & $\begin{array}{l}\text { Parcial } \\
\text { Adequado }\end{array}$ \\
\hline 2 & $\begin{array}{l}\text { Com controle = } \\
\text { Inadequado (Sacada) } \\
\text { Sem controle móvel = } \\
\text { Inadequado }\end{array}$ & $\begin{array}{l}\text { Parcialmente } \\
\text { Inadequado }=7\end{array}$ & Adequada & $\begin{array}{l}\text { Parcial } \\
\text { Inadequado }\end{array}$ \\
\hline 3 & $\begin{array}{l}\text { Com controle }= \\
\text { Adequado (Sacada) } \\
\text { Com controle móvel = } \\
\text { Adequado }\end{array}$ & Adequado $=9$ & Adequada & $\begin{array}{l}\text { Parcial } \\
\text { Inadequado }\end{array}$ \\
\hline
\end{tabular}




\begin{tabular}{|c|c|c|c|c|}
\hline 4 & $\begin{array}{l}\text { Com controle = } \\
\text { Inadequado (Sacada) } \\
\text { Com controle móvel = } \\
\text { Adequado }\end{array}$ & Adequado $=9$ & Adequado & $\begin{array}{l}\text { Parcial } \\
\text { Inadequado }\end{array}$ \\
\hline 5 & $\begin{array}{l}\text { Com controle = } \\
\text { Inadequado (Sacada) } \\
\text { Com controle móvel = } \\
\text { Adequado }\end{array}$ & Adequado $=9$ & Adequado & $\begin{array}{l}\text { Parcial } \\
\text { Inadequado }\end{array}$ \\
\hline 6 & $\begin{array}{l}\text { Com controle }= \\
\text { Adequado (Sacada) } \\
\text { Com controle móvel = } \\
\text { Adequado }\end{array}$ & Adequado $=9$ & Adequado & $\begin{array}{l}\text { Parcial } \\
\text { Inadequado }\end{array}$ \\
\hline 7 & $\begin{array}{l}\text { Com controle = } \\
\text { Adequado (Sacada) } \\
\text { Com controle móvel = } \\
\text { Adequado }\end{array}$ & Adequado $=9$ & Adequado & $\begin{array}{l}\text { Parcial } \\
\text { Inadequado }\end{array}$ \\
\hline 8 & $\begin{array}{l}\text { Com controle }= \\
\text { Adequado (Sacada) } \\
\text { Com controle móvel = } \\
\text { Adequado }\end{array}$ & Adequado $=9$ & Adequado & $\begin{array}{l}\text { Parcial } \\
\text { Inadequado }\end{array}$ \\
\hline 9 & $\begin{array}{l}\text { Com controle = } \\
\text { Inadequado (Sacada) } \\
\text { Com controle móvel = } \\
\text { Adequado }\end{array}$ & Adequado $=9$ & Adequado & $\begin{array}{l}\text { Parcial } \\
\text { Adequado }\end{array}$ \\
\hline 10 & $\begin{array}{l}\text { Com controle = } \\
\text { Adequado (Sacada) } \\
\text { Sem controle móvel = } \\
\text { Inadequado }\end{array}$ & $\begin{array}{l}\text { Parcialmente } \\
\text { Inadequado = } 7\end{array}$ & Adequado & $\begin{array}{l}\text { Parcial } \\
\text { Inadequado }\end{array}$ \\
\hline 11 & $\begin{array}{l}\text { Com controle }= \\
\text { Adequado (Sacada) } \\
\text { Sem controle móvel = } \\
\text { Inadequado }\end{array}$ & $\begin{array}{l}\text { Parcialmente } \\
\text { Inadequado }=7\end{array}$ & Adequado & $\begin{array}{l}\text { Parcial } \\
\text { Inadequado }\end{array}$ \\
\hline 12 & $\begin{array}{l}\text { Com controle = } \\
\text { Adequado (Sacada) } \\
\text { Sem controle móvel = } \\
\text { Inadequado }\end{array}$ & $\begin{array}{l}\text { Parcialmente } \\
\text { Inadequado }=7\end{array}$ & Adequada & $\begin{array}{l}\text { Parcial } \\
\text { Inadequado }\end{array}$ \\
\hline 13 & $\begin{array}{l}\text { Com controle = } \\
\text { Adequado (Sacada) } \\
\text { Sem controle móvel = } \\
\text { Inadequado }\end{array}$ & $\begin{array}{l}\text { Parcialmente } \\
\text { Inadequado = } 7\end{array}$ & Adequada & $\begin{array}{l}\text { Parcial } \\
\text { Inadequado }\end{array}$ \\
\hline 14 & $\begin{array}{l}\text { Com controle = } \\
\text { Inadequado (Sacada) } \\
\text { Sem controle móvel = } \\
\text { Inadequado }\end{array}$ & $\begin{array}{l}\text { Parcialmente } \\
\text { Inadequado }=7\end{array}$ & Adequada & $\begin{array}{l}\text { Parcial } \\
\text { Inadequado }\end{array}$ \\
\hline \multicolumn{5}{|c|}{ Joinville: 11 projetos analisados } \\
\hline 1 & $\begin{array}{l}\text { Com controle = } \\
\text { Adequado (Sacada) } \\
\text { Sem controle móvel = } \\
\text { Inadequado }\end{array}$ & $\begin{array}{l}\text { Parcialmente } \\
\text { Inadequado }=7\end{array}$ & Adequada & $\begin{array}{l}\text { Parcial } \\
\text { Adequado }\end{array}$ \\
\hline 2 & $\begin{array}{l}\text { Com controle = } \\
\text { Inadequado (Sacada) }\end{array}$ & $\begin{array}{l}\text { Parcialmente } \\
\text { Inadequado }=7\end{array}$ & Adequada & $\begin{array}{l}\text { Parcial } \\
\text { Inadequado }\end{array}$ \\
\hline
\end{tabular}




\begin{tabular}{|c|c|c|c|c|}
\hline & $\begin{array}{l}\text { Sem controle móvel = } \\
\text { Inadequado }\end{array}$ & & & \\
\hline 3 & $\begin{array}{l}\text { Com controle = } \\
\text { Adequado (Sacada) } \\
\text { Sem controle móvel = } \\
\text { Inadequado }\end{array}$ & $\begin{array}{l}\text { Parcialmente } \\
\text { Inadequado }=7\end{array}$ & Adequada & $\begin{array}{l}\text { Parcial } \\
\text { Adequado }\end{array}$ \\
\hline 4 & $\begin{array}{l}\text { Com controle = } \\
\text { Inadequado (Sacada) } \\
\text { Com controle móvel = } \\
\text { Adequado }\end{array}$ & Adequado $=9$ & Adequada & $\begin{array}{l}\text { Parcial } \\
\text { Inadequado }\end{array}$ \\
\hline 5 & $\begin{array}{l}\text { Com controle }= \\
\text { Adequado (Sacada) } \\
\text { Sem controle móvel = } \\
\text { Inadequado }\end{array}$ & Inadequado $=7$ & Adequada & $\begin{array}{l}\text { Parcial } \\
\text { Inadequado }\end{array}$ \\
\hline 6 & $\begin{array}{l}\text { Com controle = } \\
\text { Inadequado (Sacada) } \\
\text { Com controle móvel = } \\
\text { Adequado }\end{array}$ & Adequado $=9$ & Adequada & $\begin{array}{l}\text { Parcial } \\
\text { Inadequado }\end{array}$ \\
\hline 7 & $\begin{array}{l}\text { Com controle = } \\
\text { Inadequado (Sacada) } \\
\text { Sem controle móvel = } \\
\text { Inadequado }\end{array}$ & $\begin{array}{l}\text { Parcialmente } \\
\text { Inadequado }=7\end{array}$ & Adequada & $\begin{array}{l}\text { Parcial } \\
\text { Inadequado }\end{array}$ \\
\hline 8 & $\begin{array}{l}\text { Com controle = } \\
\text { Inadequado (Sacada) } \\
\text { Com controle móvel = } \\
\text { Adequado }\end{array}$ & Adequada $=9$ & Adequada & $\begin{array}{l}\text { Parcial } \\
\text { Inadequado }\end{array}$ \\
\hline 9 & $\begin{array}{l}\text { Com controle = } \\
\text { Inadequado (Sacada) } \\
\text { Sem controle móvel = } \\
\text { Inadequado }\end{array}$ & $\begin{array}{l}\text { Parcialmente } \\
\text { Inadequado = } 7\end{array}$ & Adequada & $\begin{array}{l}\text { Parcial } \\
\text { Inadequado }\end{array}$ \\
\hline 10 & $\begin{array}{l}\text { Com controle = } \\
\text { Inadequado (Sacada) } \\
\text { Sem controle móvel = } \\
\text { Inadequado }\end{array}$ & $\begin{array}{l}\text { Parcialmente } \\
\text { Inadequado }=7\end{array}$ & Adequada & $\begin{array}{l}\text { Parcial } \\
\text { Inadequado }\end{array}$ \\
\hline 11 & $\begin{array}{l}\text { Com controle = } \\
\text { Inadequado (Sacada) } \\
\text { Sem controle móvel = } \\
\text { Inadequado }\end{array}$ & $\begin{array}{l}\text { Parcialmente } \\
\text { Inadequado }=7\end{array}$ & Adequada & $\begin{array}{l}\text { Parcial } \\
\text { Inadequado }\end{array}$ \\
\hline
\end{tabular}

Fonte: Os autores

Analisando-se os dados da Tabela 8 para o conjunto de projetos avaliados para cada um dos quesitos de análise nas quatro (4) cidades, identificou-se que:

Para Blumenau, no quesito uso de elementos de controle solar nas aberturas, dos trinta e seis (36) projetos avaliados, três (3) não possuem nenhum controle solar nas aberturas; dos trinta e três (33) projetos restantes com controle solar do tipo fixo ou móvel, somente existe adequação em quinze (15) situações de controle fixo e dezenove (19) situações de controle móvel;

No quesito desempenho geral das aberturas (critérios $A, B, C$ ), em somente quatro (4) projetos existe adequação, numa dominância de trinta e um (31) projetos com parcial inadequação e um (1) com parcial adequação. 
No quesito ventilação natural cruzada, existe adequação em trinta (30) projetos;

No quesito tratamento paisagístico com sombra arbórea, existe adequação em somente um (um) projeto, parcial adequação em quatorze (14) projetos, e inadequação em vinte e dois (22) projetos.

No que se refere à análise de cada projeto de edificação em relação aos quatro (4) quesitos de análise, nenhum dos trinta e seis (37) projetos avaliados apresentaram adequação em todos os quesitos.

Existe uma situação de inadequação dominante, na sua maioria devido à ausência de controle solar nas aberturas, ou com controle solar inadequado, ou ainda pouca sombra arbórea no tratamento paisagístico exterior.

As situações de maior adequação ocorreram majoritariamente no quesito ventilação natural cruzada.

Para Florianópolis/São José, no quesito uso de elementos de controle solar nas aberturas, dos quinze (15) projetos avaliados, nenhum dos projetos não possuem controle solar nas aberturas; dos quinze (15) projetos restantes com controle solar do tipo fixo ou móvel, somente existe adequação em oito (8) situações de controle fixo e sete (7) situações de controle móvel;

No quesito desempenho geral das aberturas (critérios $A, B, C$ ), em somente nove (9) projetos existe adequação, e somente seis (6) com parcial inadequação nos demais projetos;

No quesito ventilação natural cruzada, existe adequação em trinta (15) projetos;

No quesito tratamento paisagístico com sombra arbórea, não existe adequação em nenhum projeto, parcial adequação em um (1) projeto, e inadequação em quatorze (14) projetos.

No que se refere à análise de cada projeto de edificação em relação aos quatro (4) quesitos de análise, nenhum dos quinze (15) projetos avaliados apresentaram adequação em todos quesitos.

Também para estas cidades existe uma situação de inadequação dominante, na sua maioria devido à ausência de controle solar nas aberturas, ou com controle solar inadequado, ou ainda pouca sombra arbórea no tratamento paisagístico exterior.

As situações de maior adequação ocorreram majoritariamente no quesito ventilação natural cruzada.

Para Joinville, no quesito uso de elementos de controle solar nas aberturas, dos onze (11) projetos avaliados, nenhum dos projetos não possuem controle solar nas aberturas; dos onze (11) projetos restantes com controle solar do tipo fixo ou móvel, somente existe adequação em cinco (5) situações de controle fixo e seis (6) situações de controle móvel;

No quesito desempenho geral das aberturas (critérios $A, B, C$ ), em somente três (3) projetos existe adequação, e somente oito (8) com parcial inadequação nos demais projetos;

No quesito ventilação natural cruzada, existe adequação em onze (11) projetos;

No quesito tratamento paisagístico com sombra arbórea, existe adequação em onze (11) projetos, não existe parcial adequação em nenhum projeto, e nem inadequação em projetos.

No que se refere à análise de cada projeto de edificação em relação aos quatro (4) quesitos de análise, nenhum dos onze (11) projetos avaliados apresentaram adequação em todos quesitos.

Também para Joinville existe uma situação de inadequação dominante, na sua maioria devido à ausência de controle solar nas aberturas, ou com controle solar inadequado, ou ainda pouca sombra arbórea no tratamento paisagístico exterior.

As situações de maior adequação ocorreram majoritariamente no quesito ventilação natural cruzada. 


\section{Conclusões}

Os resultados da análise das estratégias arquitetônicas de conforto ambiental presentes em projetos de edificações verticais localizadas nas quatro (4) cidades identificaram situações como adiante descrito.

Em Blumenau, existe uma situação de inadequação quanto à maior parte dos quesitos de análise.

O controle solar inadequado ou a ausência deste nas aberturas foi identificado como o maior problema nos projetos avaliados.

Já a ventilação natural foi o quesito de melhor avaliação, com situação de adequação dominante. Em boa parte isto se deve a requisitos funcionais de planta e programa de necessidades, possibilitando que existam fluxos de ar cruzados a partir de aberturas em setores sociais (salas de estar/jantar) da direção do setor íntimo (quartos), desde que as portas internas estejam abertas.

Esta situação dominante de controle solar inadequado ocorre em $89 \%$ dos ambientes de permanência dos apartamentos avaliados com existência de elementos de controle solar. Deste percentual citado, somente $71 \%$ possuem soluções adequadas (móveis e/ou fixos) e de todos apartamentos analisados, somente $18 \%$ possuem todas as soluções adequadas.

Em Florianópolis/São José, $80 \%$ possuem soluções adequadas (móveis e/ou fixos) e de todos apartamentos analisados, somente $20 \%$ possuem todas as soluções arquitetônicas de controle solar adequadas. Destes $80 \%$ que possuem alguma adequação, $53,3 \%$ existe adequação de controle fixo e $26,7 \%$ existe adequação com controle móvel.

Em Joinville, 72,7\% possuem soluções adequadas (móvel e/ou fixo) e de todos apartamentos analisados, somente $27,3 \%$ possuem todas as soluções arquitetônicas de controle solar adequadas.

O tratamento paisagístico com sombra arbórea junto ao térreo possui uma inadequação majoritária na amostra dos projetos de edifícios analisados nas 3 cidades, em boa parte por valores culturais locais (da população e dos arquitetos) de considerar a vegetação existente num terreno como um obstáculo à obra (logo, devendo ser retirada por completo), assim como uma visão dominante de paisagismo apenas contemplativo, com apenas colocação de espécies vegetais do tipo gramíneas, forragens e flores (ajardinamento).

A inadequação dominante do controle solar nos projetos analisados nas quatro (4) cidades é atribuída em grande parte devido posturas projetuais inadequadas por parte dos arquitetos, mercado imobiliário, focadas dominantemente nos resultados funcionais, volumétricos/formais e estéticos dos projetos de arquitetura.

\section{REFERÊNCIAS}

BOGO, AMILCAR JOSÉ. Clima e arquitetura em Blumenau. Blumenau: FURB, Laboratório de Conforto Ambiental, 45 p.: il. - (relatório temático 03). 1998, revisado em agosto de 2014.

FONTENELLE, M.R, CLARO, A, ARAÚJO, B.C.D. Influência de elementos de proteção solar no conforto lumínico de um edifício residencial multifamiliar em Fortaleza-CE. In.: ENCAC Encontro Nacional de Conforto no Ambiente Construído e ELACAC - Encontro Latino Americano de Conforto no Ambiente Construído, Búzios, RJ, 2011.

GUTIERREZ, G.C.R, LABAKI, L.C. Considerações sobre o brise-soleil na arquitetura moderna brasileira. In.: ENCAC - Encontro Nacional de Conforto no Ambiente Construído e ELACAC - 
Encontro Latino Americano de Conforto no Ambiente Construído, Maceió, AL, 2005.

PICCOLI JUNIOR, L.A., LETTI, A.A, HAUSSEN, A.P, BEYER, P.O. Casa protegida pela terra com energia líquida zero. In.: ENCAC - Encontro Nacional de Conforto no Ambiente Construído e ELACAC - Encontro Latino Americano de Conforto no Ambiente Construído, Brasília, 2013.

LIMA, K.M, NOGUEIRA, F.H.S, PASSOS, I.C.S, MAIA, S.S, BITTENCOURT, L.S. A influência de protetores solares na iluminação natural no edifício sede da Compesa. In.: ENCAC - Encontro Nacional de Conforto no Ambiente Construído e ELACAC - Encontro Latino Americano de Conforto no Ambiente Construído, Búzios, RJ, 2011.

MARAGNO, G.V. Eficiência e forma do brise-soleil na arquitetura de Campo Grande - MS. In.: ENCAC - Encontro Nacional de Conforto no Ambiente Construído e ELACAC - Encontro Latino Americano de Conforto no Ambiente Construído, São Pedro, SP, 2001.

SANTA CATARINA. Atlas escolar de Santa Catarina. Florianópolis. SEPLAN, 135 p., 1991.

ULIANO, Giane, BOGO, Amilcar José. Análise das estratégias arquitetônicas de controle solar em aberturas de edifícios verticais em Blumenau SC. In.: XII ENCAC - Encontro Nacional de Conforto no Ambiente Construído e VIII ELACAC - Encontro Latino Americano de Conforto no Ambiente Construído, Brasília, DF, 2013.

ULIANO, Giane, BOGO, Amilcar José. Análise das estratégias arquitetônicas de controle solar em edifícios verticais de uso comercial/serviços e residenciais: parte 2 - estudo de caso para o centro de Blumenau SC. In.: XV ENTAC 2014 - Encontro Nacional de Tecnologia do Ambiente Construído, Maceió, AL, 2014. 